\title{
Fetal Ductus Venosus Pulsatility Index and Diameter during Second and Third Trimester of Gestation
}

Pratit Pokharel, ${ }^{1}$ Mukhtar Alam Ansari ${ }^{1}$

'Department of Radiology, Institute of Medicine, Kathmandu, Nepal.

\section{ABSTRACT}

Introduction: The ductus venosus is a small funnel shaped vessel found posterior to the fetal liver connecting the intra-abdominal umbilical vein and the inferior vena cava. It is one of the three physiological shunts in the fetus. The main objective of this study is to construct the reference table and normogram for fetal ductus venosus Pulsatility Index and diameter with gestational age.

Methods: This was a prospective cross sectional study conducted during August 2011 to July 2012 taking 294 uncomplicated pregnancies using systemic random sampling method. Three measurements were made for ductus venosus diameter and Pulsatility Index in each fetus during period of fetal quiescence.

Results: The ductus venosus diameter at <20weeks, 20-25 weeks, 25-30 weeks, $>30$ weeks were 1.16, 1.31, 1.62, 1.81 and Pulsatility Index at <20weeks, 20-25 weeks, 25-30 weeks, $>30$ weeks were 0.41, $0.44,0.41$ and 0.41 respectively.

Conclusions: The mean diameter of the ductus venosus was linear across gestational age. The Pulsatility Index shows a scattered distribution across the gestational age.

Keywords: ductus venosus diameter; gestational age; Pulsatility Index..

\section{INTRODUCTION}

The ductus venosus (DV) is one of the three physiological shunts in the fetus. It has been extensively investigated in animal models. ${ }^{1,2}$

The improved color Doppler techniques help analyze the venous vessels across gestation period showing flow patterns; normal and abnormal in the human fetus. ${ }^{3,4}$ Its application has been used in fetal growth restriction, complicated monochorionic multiple gestation, fetal hydrops, and arrhythmia. ${ }^{5}$ It has also been used in detection of cardiac defects in chromosomally normal fetuses, during the first trimester scan. ${ }^{6}$ They are also useful in the management of early onset placental insufficiency and Doppler parameters correlate with $\mathrm{pH}$ at birth. ${ }^{7}$

DV Pulsatility Index (PI) along with other parameter has also been used to increase the effectiveness of the second trimester screening test. ${ }^{9}$ A normogram for DV Doppler indices has been advocated as a non-invasive tool for the evaluation of fetal cardiac function with limited confidence. ${ }^{10} \mathrm{~A}$ ductus venosus $\mathrm{PI}$ greater than the $90^{\text {th }}$ percentile was associated with aneuploidy, small for gestational age and low birth weight infants. ${ }^{11}$

The aim of the study was to find out a normal range for the ductus venosus $\mathrm{PI}$ and smallest diameter in normal fetuses throughout the gestation period.

Correspondence: Dr. Pratit Pokharel, Department of Radiology, Institute of Medicine, Kathmandu, Nepal. Email: nanupratu@gmail.com, Phone: +977-9841262000. 


\section{METHODS}

This was a prospective cross sectional study carried out in Department of Radiology \& Imaging, Tribhuvan University, Teaching Hospital from August 2011 to July 2012. The study was conducted in singleton pregnancies between 20 and 30 weeks of gestation. The ethical approval was taken from Institutional Review Board of IOM. The protocol included the Doppler interrogation of fetal ductus venosus during periods of fetal quiescence and data were used to construct the normograms and percentile fitted curves of fetal ductus venosus PI for different gestational age. Systemic Random sampling of cases were done. Every fourth case of the previous case was taken.

The patients with confirmed gestational age with normal structural scanning, negative diabetic screening at 24 to 28 weeks' gestation, without any medical or bad obstetrics history with normal previous pregnancy were included. Whereas, pregnancies of undetermined period of gestation with a history of maternal smoking, multiple pregnancies, a diagnosed fetal abnormality in current pregnancy, previous history of preeclampsia, intrauterine growth retardation, abruptio placenta or preterm delivery and not willing to give consent for the study were excluded from the study.

Patients referred for the routine obstetric examination from the department of Obstetrics and Gynecology and who met the inclusion criteria were included in the study after obtaining informed consent. Detailed information was recorded in a pre-designed data collection sheet. Information included were particulars of the patient, brief history mainly risk factors for adverse pregnancy outcome, gestational age determined from ultrasound examination before 20 weeks of gestation or from last menstrual period and the patient's blood group. While calculating the gestational age, those at 3 days and below were taken in lower gestational week and those after 4 days and above were taken in higher gestational week. For example, a patient at 20 weeks and 2 days gestation was taken as 20 weeks and a patient at 20 weeks 5 days gestation was taken as 21 weeks.

During the examination, the mother reclined supinely, with some rotation either to the right or left side to facilitate the evaluation. The ductus venosus can be visualised in its full length in mid sagittal section of the fetal trunk. In the oblique transverse section through the upper abdomen, it can be found where color Doppler indicates high velocities as compared to intra-abdominal umbilical vein. In Doppler velocimetry, the most consistent measurement could be obtained by placing the sample volume at the initial half portion of the length of the ductus venosus. The flow velocity waveform of the ductus venosus displays the continuous forward flow throughout the cardiac cycle. The ductus venosus was identified by the color aliasing of the vessel arising from the intra abdominal umbilical vein; the color scale then increased and then color gain reduced till the echogenic surfaces of the ductus venosus nearly display transparent color flow. For reduced intraobserver variations, three measurements were made in each fetus during quiescence and normograms were constructed from the results by using an average of three measurements for each normal fetus.

The statistical analysis was carried out by using SPSS software package version 17.0 (SPSS Inc., Chicago, IL, USA). Obstetric characteristics are presented as mean + standard deviation. The ductus venosus diameter and Pulsatility Index obtained from the fetuses were plotted against gestational age and the correlation coefficients were determined by using Pearson's correlation. The normal values of the ductus venosus diameter and Pulsatility Index were presented as 5th, 50th and 95th percentile ranks. P-value $<0.05$ was considered statistically significant. Normograms and percentile fitted curves were obtained.

\section{RESULTS}

Fetal ductus venosus diameter and Pulsatility Index were measured in total of 294 singleton uncomplicated pregnancy. Total 233 (79.3\%) pregnant women were in age group 20-30 and 144 (49.3\%) were primigravda (Table 1).

\begin{tabular}{|ll|}
\hline \multicolumn{2}{|l|}{ Table 1. Maternal demographics. } \\
\hline Characteristic & Number $(\mathbf{n}=\mathbf{2 9 4})$ \\
Age (mean + SD) & $26.13+3.9$ \\
Median (Inter Quartile range) & $27(29-23)$ \\
Range (max-Min) & $17(35-18)$ \\
Age Group & \\
Less than 20 & $26(8.8)$ \\
20-30 & $233(79.3)$ \\
More than 30 & $35(11.9)$ \\
Gravida & \\
Mean + sd & $2+1$ \\
Median(IQ) & $2(2-1)$ \\
Primi Gravida & $145(49.3)$ \\
Gravida 2 & $97(33.0)$ \\
Gravida 3 or more & $52(17.7)$ \\
Parity & \\
Mean + SD & $1+1$ \\
Median(IQ) & $1-0$ \\
Parity 0 & $145(49.3)$ \\
1 & $97(33.0)$ \\
2 or more & $52(17.7)$ \\
\hline
\end{tabular}


Maternal age ranged from 18 to 35 years with the mean age being $26.13 \pm 3.9$ years (Figure 1 ).

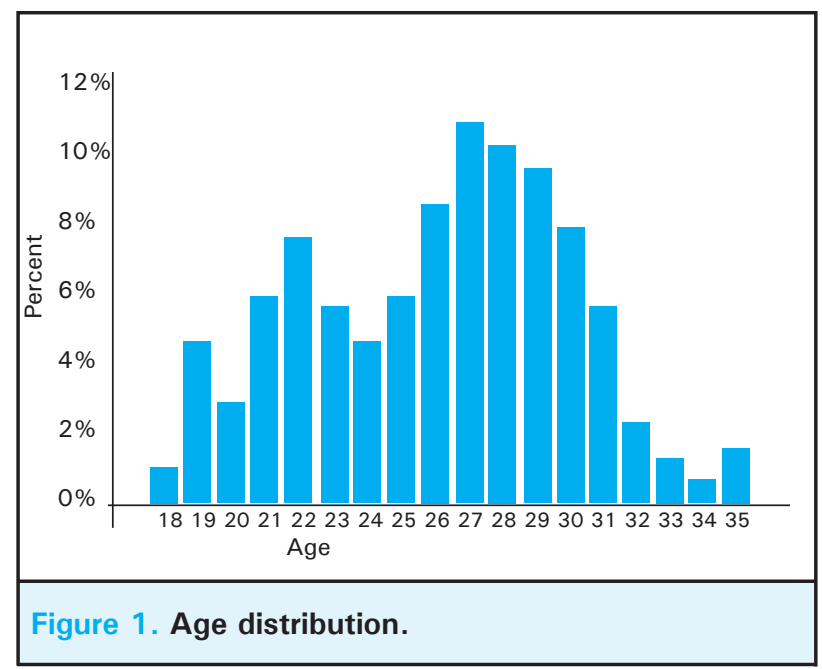

Pregnancies between 17 and 33 weeks of gestation were studied. Maximum number of pregnancies (10.5\%) was at 22 weeks of gestation. Minimum number of pregnancies $(2.0 \%)$ was at 17 weeks (Figure 2).

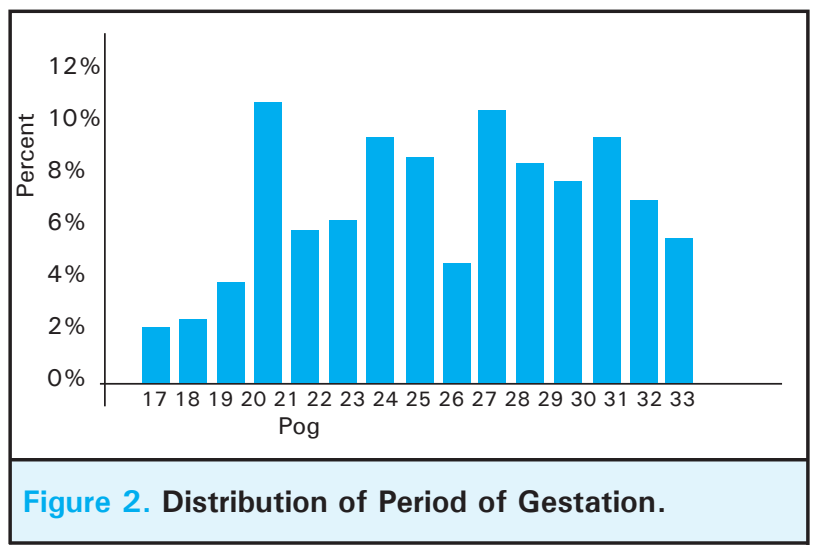

Clients were classified into 4 groups according to period of gestation; less than 20 weeks, 20-25 weeks, 25-30 weeks and more than 30 weeks. One hundred and fourteen $(38.77 \%)$ of clients were in the group 25-30 weeks period of gestation (Table 2).

\begin{tabular}{|c|c|c|c|c|}
\hline Characteristics & $<20$ weeks $(n=24)$ & $\begin{array}{l}20-25 \\
\text { weeks }(n=94)\end{array}$ & $25-30$ weeks $(n=114)$ & $>30$ weeks $(n=63)$ \\
\hline Age & $25.25+3.44$ & $25.97+3.69$ & $26.22+3.95$ & $26.56+4.25$ \\
\hline \multicolumn{5}{|l|}{ Age Group } \\
\hline$<20$ yrs & 0 & $9(9.7)$ & $13(11.4)$ & $4(6.3)$ \\
\hline $20-30$ yrs & $21(87.5)$ & $77(82.8)$ & $88(77.2)$ & $47(74.6)$ \\
\hline$>30$ yrs & $3(12.5)$ & $7(7.5)$ & $13(11.4)$ & $12(19.0)$ \\
\hline
\end{tabular}

Mean diameter of the ductus venosus diameter and the Pulsatility Index were calculated and shown (Table 3).

\begin{tabular}{|c|c|c|}
\hline POG & $\begin{array}{l}\text { Ductus venosus } \\
\text { diameter (Mean + SD) }\end{array}$ & $\begin{array}{l}\text { Ductus venosus } \\
\text { PI (Mean + SD) }\end{array}$ \\
\hline 17 & $1.07+0.03$ & $0.41+0.06$ \\
\hline 18 & $1.16+0.01$ & $0.47+0.04$ \\
\hline 20 & $1.17+0.02$ & $0.36+0.03$ \\
\hline 22 & $1.26+0.01$ & $0.40+0.02$ \\
\hline 23 & $1.30+0.02$ & $0.42+0.02$ \\
\hline 24 & $1.34+0.04$ & $0.41+0.02$ \\
\hline 25 & $1.45+0.06$ & $0.40+0.03$ \\
\hline 26 & $1.52+0.02$ & $0.50+0.02$ \\
\hline 27 & $1.57+0.03$ & $0.39+0.04$ \\
\hline 28 & $1.62+0.04$ & $0.39+0.01$ \\
\hline 29 & $1.75+0.03$ & $0.49+0.03$ \\
\hline 30 & $1.78+0.02$ & $0.44+0.03$ \\
\hline 31 & $1.80+0.02$ & $0.42+0.02$ \\
\hline 32 & $1.81+0.01$ & $0.37+0.05$ \\
\hline 33 & $1.82+0.02$ & $0.38+0.02$ \\
\hline
\end{tabular}

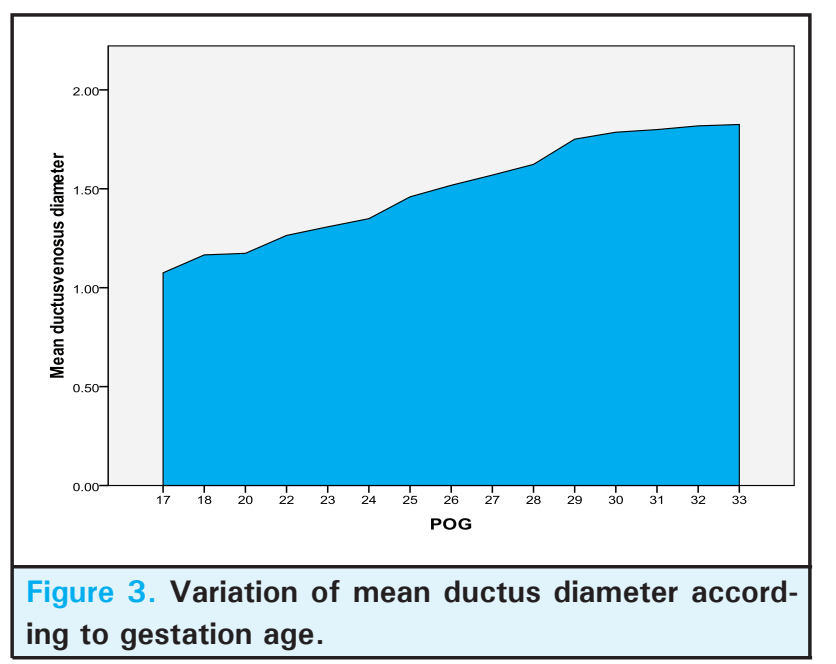




\begin{tabular}{|c|c|c|c|c|}
\hline Characteristics & $<20$ wks $(n=24)$ & $20-25$ wks $(n=94)$ & $25-30 w k s(n=114)$ & $>30$ wks $(n=63)$ \\
\hline \multicolumn{5}{|l|}{ Ductus Venosus } \\
\hline Diameter & & $1.34+0.09$ & & \\
\hline Mean + sd & $1.14+0.05$ & $1.31(1.41-1.27)$ & $1.65+0.01$ & $1.89+0.02$ \\
\hline Median(IQ) & $1.16(1.18-1.12)$ & & $1.62(1.76-1.55)$ & $1.81(1.83-1.79)$ \\
\hline \multicolumn{5}{|c|}{ Ductus Venosus PI } \\
\hline \multirow{2}{*}{$\begin{array}{l}\text { Mean } \\
\text { Median }\end{array}$} & $0.41+0.06$ & $0.41+0.02$ & $0.45+0.05$ & $0.39+0.04$ \\
\hline & $0.41(0.46-0.34)$ & $0.41(0.43-0.38)$ & $0.44(0.50-0.39)$ & $0.41(0.42-0.37)$ \\
\hline
\end{tabular}

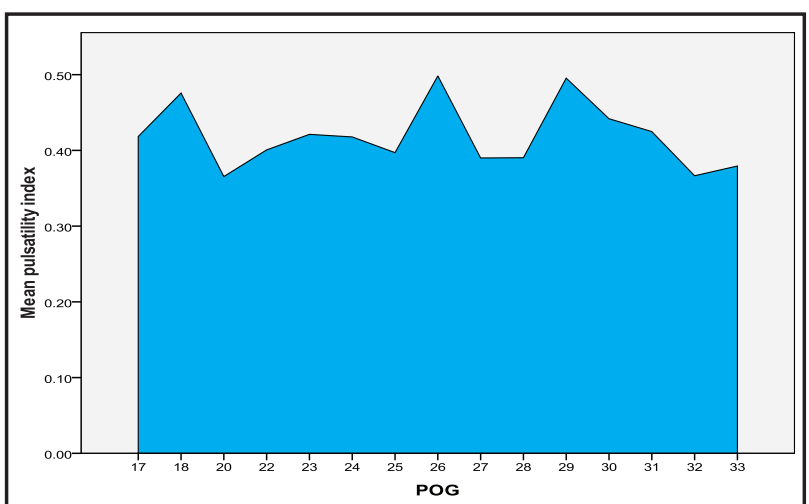

Figure 4. Variation in Pulsatility Index according to gestational age.

Ductus venosus diameter and Pulsatility Index mean and median were calculated according to the gestational age groups (Table 4).

The fetal ductus venosus diameter showed significant correlation with period of gestation. (Table 5) but did not show statistically significant correlation with ductus venosus Pulsatility Index.

Table 5. Correlation of fetal ductus venosus diameter.

Pearson's correlation
coefficient

$\begin{array}{lll}\text { POG (by date) } & 0.97 & <0.001 \\ \text { POG (by USG) } & 0.97 & <0.001 \\ \text { Ductus venosus PI } & 0.06 & 0.29\end{array}$

Table 6. Correlation of fetal ductus venosus Pulsatility Index.

\begin{tabular}{|lll|}
\hline & $\begin{array}{l}\text { Pearson's correlation } \\
\text { coefficient }\end{array}$ & p-value \\
POG (by date) & -0.024 & 0.67 \\
POG (by USG) & -0.005 & 0.97 \\
$\begin{array}{l}\text { Ductus venosus } \\
\text { diameter }\end{array}$ & 0.06 & 0.29 \\
\hline
\end{tabular}

However, fetal ductus venosus Pulsatility Index didn't show significant correlation with period of gestation or dustus venosus diameter (Table 6).

Ductus venosus diameter has significant correlation with period of gestation in each period of gestation group with best correlation in 25-30 weeks $(0.94, \mathrm{p}<0.001)$ and least in $>30$ weeks $(0.46, \mathrm{p}>0.001)$ (Table 7$)$.

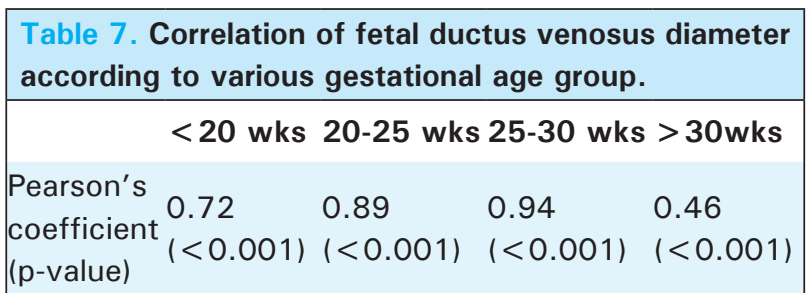

The 95th percentile of the fetal ductus venosus diameter and pulsatility indices were $1.83 \mathrm{~mm}$ (range $=0.83$ $\mathrm{mm}[1.86-1.03]$ ) and 0.51 (range $=0.26[0.56-0.30]$ ) respectively. Fetal ductus venosus diameter increases exponentially whereas PI value do not correspondingly increases with gestational age (Table 8), (Figure 6,7).

Table 8. Percentiles scores of ductus venosus diameter and Pulsatility Index according to gestationa age.

\begin{tabular}{|lll|}
\hline & $\begin{array}{l}\text { Ductus venosus } \\
\text { diameter }\end{array}$ & Ductus venosus PI \\
17 & & \\
5 th & 1.03 & 0.34 \\
50 th & 1.08 & 0.41 \\
$95^{\text {th }}$ & 1.13 & 0.52 \\
18 & & 0.43 \\
5 th & 1.15 & 0.49 \\
50 th & 1.17 & 0.52 \\
$95^{\text {th }}$ & 1.18 &
\end{tabular}




\begin{tabular}{|c|c|c|c|c|c|}
\hline \multicolumn{3}{|l|}{20} & \multicolumn{3}{|l|}{32} \\
\hline 5th & 1.14 & 0.33 & 5th & 1.77 & 0.30 \\
\hline 50th & 1.17 & 0.36 & 50th & 1.80 & 0.34 \\
\hline $95^{\text {th }}$ & 1.21 & 0.46 & $95^{\text {th }}$ & 1.82 & 0.44 \\
\hline 22 & & & 33 & & \\
\hline 5th & 1.24 & 0.34 & 5th & 1.79 & 0.36 \\
\hline 50th & 1.27 & 0.41 & 50th & 1.82 & 0.38 \\
\hline $95^{\text {th }}$ & 1.28 & 0.44 & $95^{\text {th }}$ & 1.86 & 0.42 \\
\hline
\end{tabular}

23

5th $\quad 1.25 \quad 0.37$

50th $\quad 1.31 \quad 0.43$

$95^{\text {th }} \quad 1.34 \quad 0.47$

24

$\begin{array}{lll}5 \text { th } & 1.29 & 0.38\end{array}$

$\begin{array}{lll}50 \text { th } & 1.35 & 0.41\end{array}$

$\begin{array}{lll}95^{\text {th }} & 1.41 & 0.46\end{array}$

25

5th $\quad 1.32$

0.36

50th 1.48

0.39

$95^{\text {th }} \quad 1.53$

0.46

26

5th $\quad 1.48 \quad 0.43$

50th $1.51 \quad 0.51$

$\begin{array}{lll}95^{\text {th }} & 1.56 & 0.53\end{array}$

27

$\begin{array}{lll}5 \text { th } & 1.49 & 0.37\end{array}$

$\begin{array}{lll}50 \text { th } & 1.58 & 0.37\end{array}$

$\begin{array}{lll}95^{\text {th }} & 1.60 & 0.48\end{array}$

28

$\begin{array}{lll}5 \text { th } & 1.55 & 0.36\end{array}$

$\begin{array}{lll}50 \text { th } & 1.61 & 0.39\end{array}$

$\begin{array}{lll}95^{\text {th }} & 1.70 & 0.42\end{array}$

29

$\begin{array}{lll}5 \text { th } & 1.68 & 0.39\end{array}$

50th $1.75 \quad 0.50$

$\begin{array}{lll}95^{\text {th }} & 1.80 & 0.55\end{array}$

30

$\begin{array}{lll}5 \text { th } & 1.75 & 0.42\end{array}$

50th $1.78 \quad 0.43$

$\begin{array}{lll}95^{\text {th }} & 1.82 & 0.53\end{array}$

$\begin{array}{lll}31 & & \\ 5 \text { th } & 1.76 & 0.38\end{array}$

50th $\quad 1.80 \quad 0.42$

$\begin{array}{lll}95^{\text {th }} & 1.84 & 0.47\end{array}$

The scatterplots of the fetal ductus venosus diameter and Pulsatility Index over the gestational

age are presented in Figure 5 and Figure 6 respectively.

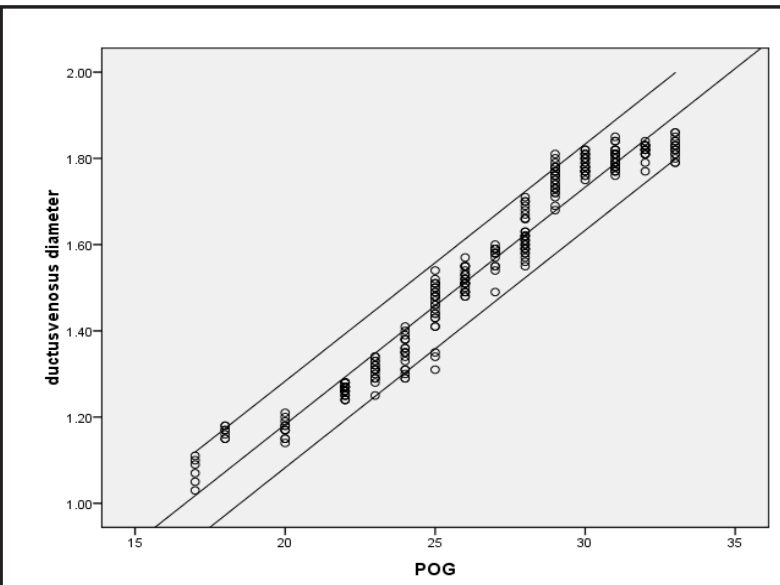

Figure 5. Scatter plot of ductus venosus diameter* according to gestational age.

*Regression line equation: $y=0.082452791738301+0.0550279$ $53924513 x$

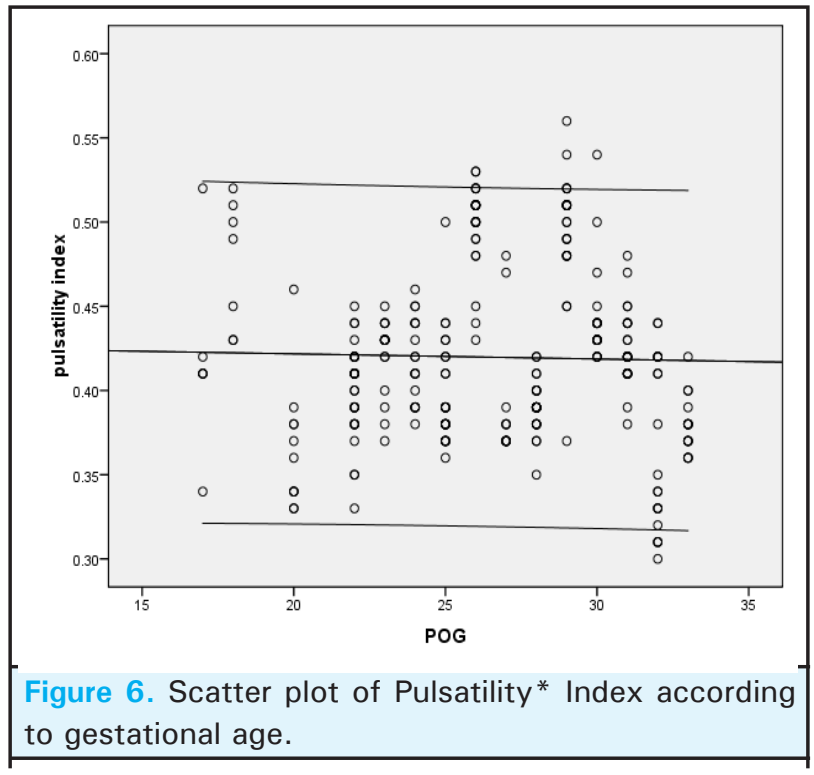

*Regression line equation: $y=0.42786784216505$ $0.0003056380072189 x$ 


\section{DISCUSSION}

Cross-sectional observations were obtained in 294 uncomplicated singleton pregnancies between 17 and 33 weeks of gestation. Reference ranges for fetal ductus venosus diameter and pulsatility index was constructed based on these observations. Continuous increasing indices of fetal ductus venosus diameter with advancing gestational age were obtained, which confirms previous observations as in my study (Table $7,8)$.

Doppler evaluation of the fetal ductus venosus has increased our depth of understanding of many fetal conditions. The ductus venosus has an important role in the regulation of nutrient partitioning in the fetus. Alterations in cardiac afterload, contractility compliance, intravascular volume status, and heart rate may significantly impact on the ductus venosus flow. Accordingly, ductus venosus Doppler is useful in the management of conditions that put the fetus at risk for cardiovascular deterioration. The application of DV Doppler in fetal growth restriction, complicated monochorionic multiple gestation, fetal hydrops, and arrhythmia has been discussed in many studies. ${ }^{5}$

Pulsatility of flow velocity waveforms in the ductus venosus are the consequence of changes in pressure difference between the venous system and the right atrium during the heart cycle. When the atrial contraction increases pressure, this is seen as a reversal in the otherwise forward flow pattern of the ductus venosus. When atrial pressure is higher during contraction the reversal pattern will be more exaggerated. The Pulsatility Index of the ductus venosus is normally below 1.0 during gestation between $2^{\text {nd }}$ trimester and term. Pulsatility above 1.0 is an indicator of high central venous pressure and a harbinger of congestive heart failure and hydrops or of right ventricular obstructive lesions such as tricuspid valve atresia. ${ }^{25}$

Our findings suggest mean diameter of ductus venosus increasing with gestational age with highest correlation seen between 25 to 30 weeks and least after 30 weeks (Table 3, 4). Chanthasenanont $A$ et al demonstrated that the mean diameter of the Ductus Venosus was linear across gestation (DV diameter $=0.36+10.04$ $x G A),(p<0.05)$ for male fetuses and DV diameter $=0.32+(0.05 \times \mathrm{GA}),(p<0.05)$ for female fetuses. ${ }^{20}$ Another studies done by Chanthasenanont A, Pongrojpaw D, Somprasit $C$ in Thailand also suggest linear association across 20 to 30 weeks gestational age however it doesn't show the variations at different gestational age. ${ }^{17}$ This shows that the ductus venosus diameter done on different populations and races shows the same linear pattern, unless proven wrong or different variation in the future.

In contrast to ductus venosus diameter, Pulsatility Index in our study doesn't correlate with gestational age and shows scattered distribution (Figure 6), however the value is below 1.0 in all gestatinal ages (Table 3,4, Figure 6). The values are relatively at stable level of 0.41 upto 25 weeks, rises in 25 to 30 weeks to 0.44 and again come back to same ranges with slight variation (Figure 6, Table 8). The study by Kessler et al, shows the Pulsatility Index for veins decreased from 0.57 at 21 weeks to 0.44 at 40 weeks. ${ }^{21}$ Notably, during the period from 14 to 20 weeks' gestation, Pulsatility Index rapidly decreased and they were relatively stable or slightly decreased after that as shown by Tongprasert et al in his study. ${ }^{10} \mathrm{~A}$ similar non linear correlation has also been demonstrated by some studies with more tendency towards a decreasing pattern. ${ }^{19}$ The possible explanation could be population variation, however more studies showing tendency towards a decreasing pattern may suggest a different explanation. Other explanation could be age related variation, difference in sample size at various gestational size and variation in technical judgement during measurement of the Pulsatility Index. Pulsatility Index values along with other parameters has also been used as a reference values in low risk pregnancy. ${ }^{22}$ Evaluation of the DV pulsatility is a useful additional variable for predicting the risk for mortality in fetuses with isolated structural CHD, in particular in fetuses with defects of the AV septum and with defects affecting predominantly right ventricular function. As there is no fetal hydrops without abnormal DV, this is another sign for the association of DV and cardiac failure. ${ }^{18}$

The limitation of the present study can be multiple. The error of judgement of the radiologist during the study period cannot be excluded. The miniature size of the ductus venosus, habitus of the patient while doing the procedure, cooperativity of the patient during study period can affect the accuracy of the results of the study. Although sample size was adequate, lack of stratification of gender, ethnicity, and probable individual genetic and anatomic variation were difficult to consider in the study which can give some variation in result. Generalization of hospital based study to the Nepalese population can also show some errors hence it is recommended that a better well designed population based epidemiological study and possibly a regional and global based study can address the various population and genetic variation and provide accuracy to the results. 


\section{CONCLUSIONS}

Reference ranges for fetal ductus venosus diameter and pulsatility indices were constructed.

Linear increment in the fetal ductus venosus diameter with advancing gestational age was obtained. The Pulsatility Index showed a scattered distribution. The present study could be used as a baseline data for evaluation of cardiovascular changes in pregnancies with fetuses at risk for hypoxia and acidemia because of anemia, congenital heart disease, congestive heart failure and intrauterine growth restriction.

\section{ACKNOWLEDGEMENTS}

We thank Dr. Pawan Kumar Hamal, Dr. Om Biju Panta, Jessica Maharjan and Leepy Paudel for their help and support during this study.

\section{Conflict of Interest: None.}

\section{REFERENCES}

1. Kiserud T, Eik-Nes S, Blaas H, Hellevik L. Ultrasonographic velocimetry of the fetal ductus venosus. Lancet. 1991;338(8780):1412-4. [PubMed]

2. Kiserud T, Eik-Nes S, Blaas HG, Hellevik L. Foramen ovale: an ultrasonographic study of its relation to the inferior vena cava, ductus venosus and hepatic veins. Ultrasound Obstet Gynecol. 2003;2(6):389-96. [PubMed]

3. Axt-Fliedner R, Wiegank U, Fetsch C, Friedrich M, Krapp M, Georg $\mathrm{T}$, et al. Reference values of fetal ductus venosus, inferior vena cava and hepatic vein blood flow velocities and waveform indices during the second and third trimester of pregnancy. Arch Gynecol Obstet. 2004;270(1):46-55. [PubMed]

4. Axt-Fliedner R, Diler S, Georg T, Friedrich M, Diedrich K. Reference values of ductus venosus blood flow velocities and waveform indices from 10 to 20 weeks of gestation. Arch Gynecol Obstet. 2004;269(3):199-204. [PubMed]

5. Baschat A, Gembruch U, Reiss I, Gortner L, Weiner C, Harman C. Relationship between arterial and venous Doppler and perinatal outcome in fetal growth restriction. Ultrasound Obstet Gynecol. 2002;16(5):407-13. [PubMed]

6. Borrell A, Grande M, Bennasar M, Borobio V, Jimenez JM, Stergiotou I, et al. First trimester detection of cardiac defects with the use of ductus venosus blood flow. Ultrasound Obstet Gynecol. 2012. [PubMed]

7. Ortigosa C, Nomura RMY, Costa VN, Miyadahira S, Zugaib M. Fetal venous Doppler in pregnancies with placental dysfunction and correlation with $\mathrm{pH}$ at birth. J Matern Fetal Neonatal Med. 2012(00):1-21. [PubMed]

8. Tseng CC, Wang HI, Wang PH, Yang MJ, Juang CM, Horng $\mathrm{HC}$, et al. Ductus venosus Doppler velocimetry in normal pregnancies from 11 to $13+6$ weeks' gestation-A Taiwanese study. Journal of the Chinese Medical Association 2012. [Full Text]

9. Demirturk F, Caliskan AC, Aytan H, Sahin S. A preliminary retrospective study about the relationship between ductus venosus Doppler indices, nuchal translucency (NT) and biochemical markers in the first and second trimester screening tests. Gynecol Endocrinol. 2012;28(5):378-81. [PubMed]
10. Tongprasert F, Srisupundit K, Luewan S, Wanapirak C, Tongsong T. Normal reference ranges of ductus venosus Doppler indices in the period from 14 to 40 weeks' gestation. Gynecol Obstet Invest. 2012;73(1):32-7. [PubMed]

11. Tsuchiya M, Kikuchi A, Takakuwa K, Tanaka K. Increased pulsatility of the ductus venosus blood velocity in the first trimester is associated with the delivery of small for gestational age or low birth weight infants. J Obstet Gynaecol Res. 2010;36(6):1151-60. [PubMed]

12. Timmerman E, Clur S, Pajkrt E, Bilardo C. First-trimester measurement of the ductus venosus Pulsatility Index and the prediction of congenital heart defects. Ultrasound Obstet Gynecol. 2010;36(6):668-75. [PubMed]

13. Rudolph AM. Hepatic and ductus venosus blood flows during fetal life. Hepatology. 1983 Mar-Apr;3(2):254-8. [PubMed]

14. Kiserud T, Hellevik L, Eik-Nes S, Angelsen B, Blaas HG. Estimation of the pressure gradient across the fetal ductus venosus based on Doppler velocimetry. Ultrasound Med Biol. 1994;20(3):225-32. [PubMed]

15. Kiserud T, Rasmussen S, Skulstad S. Blood flow and the degree of shunting through the ductus venosus in the human fetus. Am J Obstet Gynecol. 2000;182(1):147-53. [PubMed]

16. Edelstone DI, Rudolph AM. Preferential streaming of ductus venosus blood to the brain and heart in fetal lambs. Am J Physiol. 1979;237(6):H724-H9. [PubMed]

17. Coceani F, Olley P. The control of cardiovascular shunts in the fetal and perinatal period. Can J Physiol Pharmacol. 1988;66(8):1129-34. [PubMed]

18. Kiserud T, Stratford L, Hanson MA. Umbilical flow distribution to the liver and the ductus venosus: an in vitro investigation of the fluid dynamic mechanisms in the fetal sheep. Am J Obstet Gynecol. 1997;177(1):86-90. [PubMed]

19. Chanthasenanont A, Pongrojpaw D, Somprasit C. Fetal ductus venosus Pulsatility Index and diameter during 20-30 weeks gestation. J Med Assoc Thai. 2008;91(6):794-8. [PubMed] 
20. Chanthasenanont A, Pongrojpaw D, Somprasit C. Effect of fetal gender on ductus venosus pulsatility index and diameter at gestational age 17-37 weeks. J Med Assoc Thai. 2009 May;92(5):589-93. [PubMed]

21. Kessler J, Rasmussen S, Hanson M, Kiserud T. Longitudinal reference ranges for ductus venosus flow velocities and waveform indices. Ultrasound Obstet Gynecol. 2006 Dec;28(7):890-8. [PubMed]
22. Marcolin AC, Berezowski AT, Crott GC, Gonçalves CV, Duarte G. Longitudinal reference values for ductus venosus Doppler in low-risk pregnancies. Ultrasound Med Biol. 2010 Mar;36(3):392-6. [PubMed | DOI] 